\title{
The Reason Why: unravelling indirect discrimination
}

\section{Introduction}

In principle, the divide between direct and indirect discrimination is vivid. Direct discrimination deals with equal treatment, proscribing less favourable treatment because of a protected characteristic. Indirect discrimination recognises that equal treatment may itself have a disparate impact. As Baroness Hale put it in Homer, 'The law of indirect discrimination is an attempt to level the playing field by subjecting to scrutiny requirements which look neutral on their face but in reality work to the comparative disadvantage of people with a particular protected characteristic.' ${ }^{1}$ The focus is on the impact rather than the treatment: while direct discrimination requires a showing that the less favourable treatment was 'because of' the protected characteristic, it is the disparate impact of an apparently neutral requirement that establishes a prima facie case of indirect discrimination. The respondent's opportunity to explain the requirement comes in the form of the justification defence, which the court will scrutinise to determine whether it is a proportionate means of achieving a legitimate aim. This structure is epitomised in the EU Race Directive, which defines indirect discrimination as occurring when 'an apparently neutral provision, criterion or practice would put persons of a racial or ethnic origin at a particular disadvantage compared with other persons, unless that provision, criterion or practice is objectively justified by a legitimate aim and the means of achieving that aim are appropriate and necessary. ${ }^{2}$ Yet in the recent Essop case, ${ }^{3}$ the Court of Appeal has insisted that the applicants establish, not just that the provision, criterion or practice (PCP) in fact puts people with a protected characteristic at a particular disadvantage, but also the 'reason why' the PCP does so. This is before the burden shifts to the respondent to justify the PCP. This approach has been followed by the Court of Appeal in the more recent Naeem case. $^{4}$

The result is to shift the focus away from the key principle of indirect discrimination articulated in Homer, namely to subject apparently neutral requirements to scrutiny in order to level the playing field. The key issue should not be to determine why a PCP has disadvantageous effects

\footnotetext{
${ }^{1}$ Chief Constable of West Yorkshire Police v Homer (2012) UKSC 15 (UK Supreme Court), para 17.

${ }^{2}$ Racial Equality Directive 2000/43/EC Article 2(2)(b).

${ }^{3}$ Essop and others $v$ Home Office (UK Border Agency) [2015] EWCA 609

${ }^{4}$ Naeem $v$ Secretary of State for Justice [2015] EWCA 1264
} 
on people with a protected characteristic, but whether it can be justified in the light of possible alternatives, and if not, how it should be modified or replaced. Instead, the line of reasoning adopted by the Court of Appeal in Essop and Naeem blurs the boundary between direct and indirect discrimination, and indeed risks rendering indirect discrimination otiose. Sir Colin Rimer stated in Essop that the 'reason why' question in indirect discrimination case is of a different nature to that in direct discrimination cases, because it 'does not go to the employer's motive or intention, whether conscious or unconscious. It is as to why the PCP disadvantages the group sharing the protected characteristic. ${ }^{5}$ However, in at least some categories of direct discrimination cases, the respondent's motive or intention has been held to be irrelevant. Thus, according to Lord Goff: 'The intention or motive of the defendant to discriminate . . is not a necessary condition of liability. ${ }^{6}$ In such cases, direct discrimination occurs if, 'but for' the protected characteristic of the complainant, she would not have been treated less favourably. ${ }^{7}$ Further, if the reason why question requires the applicant to prove that the PCP's disparate impact was because of a protected characteristic, the claim could just as well be brought as one of direct discrimination as indirect discrimination.

\section{Essop}

Essop was concerned with the paradigmatic case of indirect discrimination: namely, the disparate impact of apparently neutral selection tests for recruitment, promotion and training. In this case, the test in question was the Core Skills Assessment (CSA) which was necessary to pass in order to achieve promotion to the post of Higher Executive Officer or above in the Civil Service. In a set of test cases challenging the CSA as indirectly discriminatory, it was asserted that black and minority ethnic (BME) candidates over the age of 35 were systematically less likely to pass than non-BME and younger candidates. This was based on a statistical report (the Kandola report) commissioned by the Government, which found that BME and older candidates had a proportionately lower CSA pass-rate than white and younger candidates. Indeed, according to the report, the selection rate of BME candidates was only $40.3 \%$ of that of whites and that of older candidates was $37.4 \%$ of that of whites. These remarkable disparities were highly unlikely to have occurred by chance. In statistical terms, the risk of this having occurred by chance was only $0.1 \%$. The complainants argued that this was indirectly discriminatory under section 19 of the Equality Act (EA) 2010. The claim came to

\footnotetext{
${ }^{5}$ Essop and others v Home Office (UK Border Agency) para 58.

${ }^{6} R$ v Birmingham City Council, Ex p Equal Opportunities Commission [1989] AC 1155 (HL), para 175.

${ }^{7}$ James $v$ Eastleigh BC [1990] 2 AC 751 (HL); R (on the application of E) $v$ Governing Body of JFS and the Admissions Appeal Panel of JFS [2009] UKSC 15
} 
the Court of Appeal on the preliminary issue of whether, as well as showing disparate impact, the applicants were also required to establish the reason for that impact.

Indirect discrimination is defined by sub-s 19(2) of the EA 2010. Section 19(2) states that a $\mathrm{PCP}$ is 'discriminatory in relation to a relevant protected characteristic of B's if:

(a) A applies, or would apply, it to persons with whom B does not share the characteristic,

(b) it puts, or would put, persons with whom B shares the characteristic at a particular disadvantage when compared with persons with whom B does not share it,

(c) it puts, or would put, B at that disadvantage, and

(d) A cannot show it to be a proportionate means of achieving a legitimate aim.'

In the EAT, Langstaff $\mathrm{J}$ held that there was no need to prove the reason why a statistical disparity arose. ${ }^{8}$ However, the Court of Appeal held that the statistical disparity was not sufficient. In addition, Sir Colin Rimer stated, the claimant had to establish 'why the PCP disadvantages the group sharing the protected characteristic.' ${ }^{9}$ Indeed, he held, 'it is conceptually impossible to prove a group disadvantage for the purpose of sub-s 19(2)(b) liability without also showing why the claimed disadvantage is said to arise. ${ }^{10}$ This was despite the fact that, as he acknowledged, no reason had been provided by the Kandola report for this differential outcome and that it would in all likelihood be impossible to prove what the reason for the disparity was.

Sir Colin gave several reasons for this conclusion. Firstly, he stated, both direct and indirect discrimination claims require the claimant to prove the 'reason why' although in different ways. 'In a direct discrimination claim, the claimant must prove that the respondent's discriminatory treatment of him was because of, or on the grounds of, his protected characteristic. He must, therefore, if he is to succeed, show that to be the answer to 'the reason why' question which arises in such claims. In indirect discrimination claims, there is also a necessary "reason why" question but it is of a different nature. It does not go to the employer's motive or intention, whether conscious or unconscious. It is as to why the PCP disadvantages the group sharing the protected characteristic."11

\footnotetext{
8 [2014] I.C.R. 871; see S Fredman, 'Addressing Disparate Impact: Indirect Discrimination and the Public Sector Equality Duty' (2014) 43 Industrial Law Journal 349.

9 Para 59.

${ }^{10}$ Para 59, emphasis in the original.

${ }^{11}$ Essop and others $v$ Home Office (UK Border Agency) para 58.
} 
Secondly, while he agreed with Langstaff $\mathrm{J}$ that section 19 does not in terms require the members of the disadvantaged group to show why they have suffered the disadvantage, Sir Colin regarded this as a 'somewhat literal interpretation of the statutory language' which 'overlooks that it is conceptually impossible to prove a group disadvantage for the purpose of subsection 19(2) (b) without also showing why the claimed disadvantage is said to arise. ${ }^{12}$ Group disadvantage could not be proved in the abstract. Its proof required a demonstration of 'why the comparative exercise inherent in the section 19(2)(b) inquiry results in the claimed disadvantage. ${ }^{13}$ This issue, in his view, was immediately related to the subsection 19(2)(c) inquiry, which requires the claimant to show that the PCP 'puts, or would put, B at that disadvantage'. This led him to uphold Employment Judge Baron's view that each claimant must prove the nature of the group disadvantage for subsection 19(2)(b) and that she suffered the same disadvantage for subsection 19(2)(c).

Thirdly, he rejected the view that the group disadvantage consisted of the 'actual failure' or 'mere fact of failure of the test.' This was incorrect, he held because 'many BME and older candidates did pass the test and there is no logical warrant for an assertion that any who did not pass failed it only because of the disadvantage to the group posed by the CSA. The most that can be derived from the ... Kandola report is that the claimants belonged to a group whose members were, by reason of one or more factors related to their shared protected characteristic, disproportionately more likely than the comparators to fail the CSA. ${ }^{14}$ Although this was the disadvantage to which the group as a whole was subject, it did not follow that 'each claimant's failure was the consequence of any such factors. ${ }^{, 15} \mathrm{He}$ did, however, hold that it would be possible for the claimant to submit that, in the absence of any other explanation, the Kandola report proves facts from which the tribunal could decide that the discrimination case is proved, subject to the justification defence. ${ }^{16}$ On the other hand, if any claimant is not found to have been subject to the same disadvantage as the group as a whole, then the tribunal has no jurisdiction to grant a remedy in that claimant's claim and should dismiss it. All of this is before we even get to the respondent's justification claim: if the claimant gets as far as satisfying all the requirements in 19(1)(a) (the PCP), 19(1)(b) (the group disadvantage) and 19(1)(c) (the

\footnotetext{
${ }^{12}$ Ibid. para 59, emphasis in the original.

${ }^{13}$ Ibid. para 59.

${ }^{14}$ Ibid. para 62.

${ }^{15}$ Ibid. para 62 , emphasis in the original.

${ }^{16}$ Ibid. para 64.
} 
individual disadvantage), it is still open to the Home Office to seek to justify the PCP under subsection 19(1)(d).

\section{Discussion}

The Essop decision is problematic for several reasons. The first is the way in which the 'group' disadvantage is understood. Systematic statistical disparities in test outcomes, which cannot be attributed to chance, signify that there is a lower probability that a BME candidate will be successful than white candidates. ${ }^{17}$ A lower probability does not mean that every BME candidate will fail, nor that all white candidates will pass. However, because the foundational premise of anti-discrimination law is that merit is equally spread as between white and BME populations, success rates should be broadly similar. A disparity in success rates therefore implies that the playing field is not level. It is precisely such a scenario that indirect discrimination aims to address, as Baroness Hale emphasized in Homer.

A finding of disparate impact does not, however, entail that, were it not for this particular test or requirement, any specific BME candidates would be successful. The logical outcome should be for a fairer test to be devised, which gives all candidates an equal chance of success. The candidate who would have failed on a fair test will still fail, this time for the right reasons. The approach taken by the Court of Appeal, however, puts the burden on the candidate to demonstrate that, but for the unfairness of the test, she would have passed. This looks similar to a direct discrimination claim, which requires the claimant to show that, but for her race or ethnic origin, she would not have been subjected to a given detriment. ${ }^{18}$ However, it is precisely because the test does not disqualify all BME candidates that indirect discrimination is needed. The real aim of indirect discrimination is to require tests to give equal opportunities to both white and BME candidates to pass or to fail.

The above analysis gains support from EU law. In the recent case of $\mathrm{CHEZ},{ }^{19}$ the CJEU was asked to determine the meaning of the indirect discrimination provisions in the Racial Equality Directive 2000/43 and in particular, the terms 'apparently neutral practice' and 'put persons of a racial or ethnic origin at a particular disadvantage compared to others' in Article 2(2)(b) of the Directive. The Court made it clear that, for a measure to be capable of being indirect discrimination, it is 'sufficient that, although using neutral criteria not based on the protected

\footnotetext{
17 This discussion focuses on the racial ground, but similar arguments can be made in relation to age.

${ }^{18}$ James $v$ Eastleigh Borough Council [1990] 2 AC 751 \&R. (on the application of E) v JFS Governing Body [2009] UKSC 15, [2010] 2 AC 728.

${ }^{19}$ C-83/14 CHEZ Razpredelenie Bulgaria AD v Komisia za zashtita ot diskriminatsia [2016] 1 CMLR 14 (CJEU (Grand Chamber)).
} 
characteristic, it has the effect of placing particularly persons possessing that characteristic at a disadvantage. ${ }^{20}$ There is no mention of a requirement that the complainant give the reason why it has this effect.

This highlights the second and related problem with the Court of Appeal's decision, namely the burden of proof. It was recognised early on in the development of discrimination law in the $\mathrm{UK}$ and the EU that the complainant might often be in no position to prove that the respondent had in fact discriminated either directly or indirectly. The EU burden of proof directive therefore held that once a prima facie case had been established, the burden should shift to the respondent ${ }^{21}$ and this is now captured both in the Racial Equality Directive ${ }^{22}$ and the EA $2010 .^{23}$ In Essop, the Court of Appeal seems to be moving in the opposite direction. Although a disparate impact should be sufficient to establish a prima facie case, the Court places an extra burden on the claimant, that of proving why the disparate impact occurred. Moreover, Sir Colin acknowledged that in this case, it would very likely be impossible for the applicant to discharge. This is difficult to square with either EU law or the EA itself. Article 8(1) of the Racial Equality Directive (2000/43) requires member states to make provision that, when complainants 'establish ...facts from which it may be presumed that there has been direct or indirect discrimination, it shall be for the respondent to prove that there has been no breach of the principle of equal treatment.' Similarly, subs 136(2) of the EA 2010 provides: 'If there are facts from which the court could decide, in the absence of any other explanation, that A contravened the provision concerned, the court must hold that the contravention occurred' unless A can show that A did not contravene the provision. It was precisely for situations in which it would be very difficult or impossible for a claimant to prove more than the facts establishing the prima facie case that the shift in the burden of proof was put in place. At the very least, then, the Court of Appeal should have held that the disparate impact constituted sufficient facts for the burden to shift to respondent to establish 'the reason why'.

The third difficulty with the decision in Essop concerns the relationship between establishing the group disadvantage in subsection 19(1)(b) and individual disadvantage in subsection 19(1)(c). Both the employment tribunal and the Court of Appeal put much weight on the words in subsection 19(1)(c) referring to 'that disadvantage' (emphasis added). In their view, these words mean that the individual must suffer the same disadvantage for the purposes of

\footnotetext{
${ }^{20}$ Ibid. para 96.

${ }^{21}$ Burden of Proof Directive (97/80/EC).

${ }^{22}$ Article 8(1).

${ }^{23}$ Section 136(2).
} 
subsection 19(1)(c) as the group does for the purposes of subsection 19(1)(b). This in turn was held to influence the way in which the words 'particular disadvantage' were interpreted in subsection 19(1)(b). It is striking, however, that the requirement of a separate proof of individual disadvantage, such as that in subsection 19(1)(c), is nowhere to be found in the Race Equality Directive, which merely provides that 'indirect discrimination shall be taken to occur where an apparently neutral provision, criterion or practice would put persons of a racial or ethnic origin at a particular disadvantage compared with other persons, unless that provision, criterion or practice is objectively justified by a legitimate aim and the means of achieving that aim are appropriate and necessary. ${ }^{24}$ It is therefore arguable that placing this extra requirement on the individual is not compatible with the EU directive.

The absence of the individual requirement in EU law should, at the very least, mean that subsection 19(1)(c) should be given a broad interpretation rather than the very restrictive approach of the Court of Appeal in Essop. This is in line with the history of the provision in UK law too. The original definitions of indirect discrimination in the Race Relations Act 1976 (RRA) and the Sex Discrimination Act 1975 (SDA) included an individual component in that the complainant was required to show that the requirement or condition was to her detriment because she 'cannot comply with it'. ${ }^{25}$ Even so, the UK courts preferred a broad rather than literal interpretation of this provision in order to ensure that groups defined by their ethnic origin were not deprived of the protection intended by the Act. Thus in Mandla v Lee, Lord Fraser stated that 'a literal reading of the word 'can' would deprive Sikhs and members of other groups defined by reference to their ethnic origins of much of the protection which parliament evidently intended the Act to afford them. ${ }^{26}$ Therefore, he held, that the use of the word 'can' must have been intended to mean not 'can physically', but 'can in practice' or 'can consistently with the customs and cultural conditions of the racial group. ${ }^{, 27} \mathrm{He}$ likewise endorsed the EAT's use of this interpretation in the similarly worded SDA in Price v Civil Service Commission. ${ }^{28}$ The change in the wording from 'can comply' to 'that disadvantage' arguably is required by the move to 'particular' disadvantage from the previous wording (which referred to a requirement or condition with which a considerably smaller number of persons of the complainant's ethnic group 'can comply'), rather than signalling a change in meaning or

\footnotetext{
${ }^{24}$ Directive 2000/43, Article 2(2)(b).

${ }^{25}$ SDA 1975, s.1(1)(b)(iii); RRA s1(1)(b|)(iii)).

${ }^{26}$ Mandla v Lee [1983] 2 AC 548 (HL) at 565G.

${ }^{27}$ Ibid. at $566 \mathrm{~A}$.

${ }^{28}$ Price v Civil Service Commission (No.1) [1978] I.C.R. 27 (EAT).
} 
approach. Moreover, when the SDA was amended in 2001 to comply with the definition of indirect discrimination which had been introduced in the Burden of Proof Directive ${ }^{29}$ this did not require the complainant to show that she 'cannot comply' with the provision, merely that it was to her detriment. ${ }^{30}$ It is true that subsection 19(1)(c) by referring to 'that disadvantage', appears to draw a link to the 'particular disadvantage' referred to in s19(1)(b). However, given the highly restrictive result of this interpretation, and the absence of any such restriction in the Race Directive, it is submitted that the Court of Appeal should have taken its cue from the well established approach in the previous legislation to give a broad and purposive interpretation.

This analysis too is borne out by the approach of the Grand Chamber of the CJEU in CHEZ. In this case, the CJEU held that the words 'particular disadvantage' in the Race Directive should be interpreted to denote that 'it is particularly persons of a given ethnic origin who are at a disadvantage,' rather than requiring serious, obvious or particularly significant cases of inequality. ${ }^{31}$ In other words, the 'particular' refers to those who are affected rather than the nature of the disadvantage.

The Court of Appeal in Essop nevertheless regarded the requirement of individual disadvantage as central to its analysis of both the individual disadvantage provision in subsection 19(1)(c) and the group disadvantage provisions in subsection 19(1)(b). Sir Colin Rimer, like Baron J in the employment tribunal, was very preoccupied with what he called the 'coat-tailer', the person who failed for a different reason than the reason why the test has disparate results. The coattailer appears to be the person who would have failed in any event, possibly through lack of sufficient effort, ability or even punctuality. This person, it seems, should not be allowed to challenge the disparate outcome. It is true that the wording of subsection 19(1)(c), as was repeatedly emphasized Sir Colin, requires the complainant to establish that she suffered from 'that disadvantage', the implication being that she suffered from the same disadvantage as under the group provision in subsection 19(1)(b), namely an unfair test, rather than lack of application or merit. Sir Colin took the view that the disadvantage in subsection 19(1)(b) constituted the risk of failure, which was different from the fact of failure. The risk of failure, in his view, could not be experienced by an individual and therefore could not constitute the disadvantage at issue for subsection 19(1)(c). However, it is respectfully submitted that, as the above analysis shows, this misunderstands the meaning of risk and probability. Each BME

\footnotetext{
${ }^{29}$ Directive $97 / 80 /$ EC.

${ }^{30}$ SI 2001/2660 reg 2.

${ }^{31}$ CHEZ Razpredelenie Bulgaria AD v Komisia za zashtita ot diskriminatsia para 109, emphasis added.
} 
candidate faces a heightened risk of failure but this risk does not materialise for each individual. This is precisely the meaning of risk and probability.

The preoccupation with the 'coat-tailer' reflects a deeper ambivalence about the meaning of indirect discrimination. The focus on what is considered to be an 'unmeritorious' applicant goes against the fundamental premise, articulated by Baroness Hale, namely that the aim is to level the playing field, rather than to benefit specified individuals. If the selection test can be modified to test the appropriate skills in ways which give everyone a fair opportunity, then the law should require the respondent to do so. On the other hand, the employer is not required to sacrifice the quality of employees. If the test can be shown justified on the basis that precisely this test is necessary in order to find candidates with the appropriate skills for the job, then the employer or other respondent need not change its practice. In principle, other ways of equalising opportunity should be found.

A good way of illustrating this is to use the example drawn on by Employment Judge Baron, namely a test requiring a high level of spoken English, which put BME candidates generally at a particular disadvantage, but did not affect the particular claimant who had a high level of spoken English but still failed the test. According to Employment Judge Baron, to allow such a claimant to succeed would permit her to benefit from a 'statistical fluke. ${ }^{32}$ However, the notion of a statistical fluke is self-contradictory: the meaning of probability is precisely that the outcome would not have occurred by chance. On the other hand, if the aim of the exam is to test spoken English, then there must be something wrong with the exam if a good English speaker fails. If the aim is to test other qualities, and candidates with these qualities but who do not have good spoken English fail the test, then there is also something amiss with the test. The only way through this conundrum is to ask the respondent to justify the test: namely to specify what qualities it is testing, whether these qualities are required for the job, and whether given the disparate impact, this is a proportionate means of finding the right candidates for the job.

Some of these difficulties arise because the case came up as a preliminary matter, so that neither justification nor remedies were directly at issue. Yet the court was clearly influenced by these issues. Thus Sir Colin, referring to Langstaff J's decision that proof of disparate impact was sufficient for subsection 19(1)(b), stated: "I interpret his decision as being to the effect that (subject always to objective justification) the claimants will have an automatic ride to

\footnotetext{
${ }^{32}$ Cited in Essop and others v Home Office (UK Border Agency) para 25.
} 
victory. ${ }^{33}$ Yet the objective justification is clearly the key to the issue. The respondent's opportunity to show that the test is a proportionate means of achieving the legitimate objective of selecting the right candidates for promotion despite its disparate impact should be the heart of the case, rather than leaving the burden on the applicant to prove the reason why. Similarly, the Court refers to the effect of the EAT's decision on remedies, although, being a preliminary matter, it was not required to consider remedies expressly. Langstaff $\mathbf{J}$ dealt with the coat-tailer difficulty by suggesting that if the individual did not suffer detriment because she would have failed even under a 'fair' test, then she should not be awarded compensation. Sir Colin rejected this approach, noting that this was not a realistic scenario since it was impossible to tell who is a coat-tailer. Instead, his solution was to hold that if the complainant had not suffered detriment, she would not have made out her case under subsection 19(1)(c) and therefore the claim would not even have progressed to justification stage, never mind remedial stage.

However, neither of these is the appropriate response. The only way forward is to run a fair test and let those who are meritorious succeed. It is misleading to characterise the result of a successful indirect discrimination claim as giving the individual claimant the sought-after promotion. What the claimant should get is a fair chance through a fair test. This highlights the difficulty of seeing remedies for indirect discrimination in terms only of compensation. If a PCP is shown to have disparate effect which cannot be justified, the logical conclusion is that it should be modified. The tribunal does not have power to make such an order. It does, however, have power to make a recommendation under section124 of the Act, although the inventive possibility of a 'wider recommendation' has now been removed. The aim of this litigation should be to modify the PCP, rather than focussing only on providing compensation. As Baroness Hale put it in Homer, 'The resulting scrutiny may ultimately lead to the conclusion that the requirement can be justified. But if it cannot, then it can be modified so as to remove the disadvantage. ${ }^{34}$

This approach can be seen in other jurisdictions, such as Canada, where systematic disparate results of selection testing have been challenged as indirectly discriminatory. In the Canadian case of Meiorin ${ }^{35}$ new fitness tests were introduced for firefighters in the Canadian province of British Columbia. It was established that 65 percent to 70 percent of male applicants passed the tests on their initial attempts, while only 35 percent of female applicants have similar

\footnotetext{
${ }^{33}$ Ibid. para 35.

${ }^{34}$ Chief Constable of West Yorkshire Police v Homer para 17.

${ }^{35}$ British Columbia (Public Service Employee Relations Commission) v. B.C.G.E.U. (1999) 3 SCR 3 (Supreme Court of Canada).
} 
success. The applicant, who had already been employed as a firefighter for some years and had performed satisfactorily, failed the aerobic test on four occasions, and was dismissed. It was also shown that most women have a lower aerobic capacity than most men, and, unlike most men, most women cannot increase this with training. Clearly, 35\% of women could meet this standard, and 30 to $35 \%$ of men could not. Nevertheless, the Supreme Court of Canada held that the disparate outcome was sufficient to establish a prima facie case of disparate impact. Of course, the applicant might well have been a coat-tailer in the sense identified by Sir Colin in that she might have been in the $35 \%$ of women with sufficient aerobic capacity but simply did not train enough to pass the test. But this was not what concerned the court. The applicant did not have to prove that there was no other reason for her failure than that she physiologically was unable to meet the aerobic capacity required. It was sufficient that most women would have been unlikely to. This was because it was not assumed that by permitting her to succeed at the prima facie stage, the province would need to guarantee a position to an unmeritorious applicant, nor to provide her with compensation. The focus was instead on the question whether the standard could be adapted to ensure that firefighters were sufficiently fit to perform their jobs while at the same time giving women and men an equal opportunity to obtain this level of fitness.

\section{Naeem}

The focus on the 'reason why' was further endorsed by the more recent Court of Appeal decision Naeem $v$ Secretary of State for Justice. ${ }^{36}$ In this case, a Muslim prison chaplain challenged the pay scale for prison chaplains on the grounds that it was indirectly discriminatory. Until 2002, only Christian prison chaplains were employed, there being no perceived need for Muslim chaplains. Because prison chaplains' pay is based on years of service, requiring nine years to reach the top of the pay scale, no Muslim chaplains had joined several Christian counterparts at the top of the pay scale. Mr Naeem, a Muslim chaplain, claimed that this was indirectly discriminatory because of religion. The employment tribunal found that the scheme was prima facie indirectly discriminatory, but could be justified as a proportionate means of achieving a legitimate aim. In rejecting the applicants' appeal, both the EAT and the Court of Appeal (albeit for different reasons) preferred to find that there had been no prima facie case of indirect discrimination, thus relieving the respondent of the need to prove justification. Underhill LJ in the Court of Appeal did not accept that it was sufficient to show that the length of service criterion led to a disparity in pay between Muslim and Christian prison

\footnotetext{
${ }^{36}$ Naeem $v$ Secretary of State for Justice
} 
chaplains. It was open to the respondent to 'go behind the bare fact that Muslim and Christian chaplains have different lengths of service and to seek to establish the reason why that was so. ${ }^{37}$ In his view, the only material cause of the disparity was the more recent start-dates of the Muslim chaplains. 'But that does not reflect any characteristic peculiar to them as Muslims: rather it reflects the fact that there was no need for their services (as employees) at any earlier date. ${ }^{38} \mathrm{He}$ contrasted this with length of service criterion which had 'an inherent tendency to put women at a disadvantage because women are liable to start their careers later than men and/or take career breaks because of family and childcare responsibilities'. ${ }^{39}$ In the current case, however, the shorter average length of service of Muslims was attributable to a fact - a growing proportion of Muslim prisoners - 'which does not operate to the disadvantage of Muslims. ${ }^{40}$ He thus rejected the employment tribunal's approach, namely that once the disparity had been established, the burden shifted to the employer to justify it.

For this, he relied not just on the Essop case but also on the line of cases under the previous Equal Pay Act 1970 which had grappled with the role of indirect discrimination under statutory wording which had never contemplated the principle. ${ }^{41}$ Underhill LJ regarded this case-law as of continuing relevance to the EA 2010, but somewhat surprisingly made no reference to the helpful way in which the EA 2010 has changed the wording of the equal pay provisions in relation to gender. ${ }^{42}$ The statute now distinguishes between a defence based on a material factor which is expressly based on sex and one which, while not expressly treating a woman less favourably on grounds of her sex, nevertheless puts her at a particular disadvantage compared to a man doing equal work. In the second case, the burden of justification is not discharged unless the material factor cited in defence is a proportionate means of achieving a legitimate aim. For example, if an employer seeks to justify paying part-time workers less on the grounds that they work part time, it would be relying on a material factor which puts women at a particular disadvantage when compared with men. In such circumstances, the defence cannot succeed unless the employer can show that paying part-time workers less is a proportionate means of achieving a legitimate aim. In both cases, however, the burden shifts to the employer

\footnotetext{
${ }^{37}$ Ibid. para 22.

${ }^{38}$ Ibid. para 22.

${ }^{39}$ Ibid. para 23 citing Health and Safety Executive v Cadman [2005] ICR 1546 (CA).

${ }^{40}$ Ibid. para 24.

${ }^{41}$ S Fredman, "Reforming Equal Pay Laws" [2008] 37 ILJ 193 - 218

${ }^{42}$ EA 2010, s.69.
} 
to justify the difference as soon as a woman shows that she has been paid less than a man doing like work or work of equal value in the same establishment for the same employer.

It is notable that there is some ambiguity in Naeem as to who is responsible for establishing the reason why. Underhill LJ acknowledged that Essop could be read as suggesting that the burden of proving the reason is in all cases on the claimant. However, he points to a later passage from Sir Colin's judgment to suggest that this was not his view. This is the paragraph in which Sir Colin left it open to the applicant to submit that the Kandola report proved facts which 'in the absence of any other explanation, the employment tribunal could decide that (subject to objective justification) the discrimination case is proved: see section $136 .{ }^{43}$ Underhill LJ himself appears to suggest that it is up to the employer to rebut a claim of indirect discrimination by showing that an apparent disparate impact is the result of non-discriminatory factors. ${ }^{44}$ Why then was Underhill LJ reluctant to deal with the latter arguments under the justification defence? His response is revealing. 'It is not always straightforward', he held, 'to prove that a particular pay practice is justified.' Such an inquiry might expose all kinds of unfairness which are not the business of the 2010 Act to address, 'and respondents ought not to have to defend them unless there is in truth an element of discrimination. ${ }^{45}$

There are two connected difficulties with this. The first is the ambiguity around the meaning 'discrimination' in this dictum. If 'discrimination' means, as Underhill LJ seems to suggest, that the cause of the disadvantage is due to 'any characteristic peculiar to them as Muslims', then it is only direct discrimination to which he is alluding. Yet the point of indirect discrimination is precisely that there is no disparate treatment on the basis of a characteristic peculiar to a protected characteristic. Instead, the aim is to scrutinise the PCP which has such an effect to determine whether there is another way of achieving a legitimate objective which has a lesser impact. Secondly, by front-loading the discrimination inquiry in the way suggested by Essop and Naeem, there is no opportunity to canvass such alternatives. In Homer, Baroness Hale made it clear that the justification question depends to some extent on whether there are non-discriminatory alternatives available. ${ }^{46}$ The EAT in Naeem took this seriously. Although it held that there was no prima facie discrimination, it did go on to consider the justification defence in the alternative. In this respect, it held that there were sufficiently obvious alternatives to a pay-scale based purely on seniority for the employment tribunal to have

\footnotetext{
${ }^{43}$ Essop and others $v$ Home Office (UK Border Agency) para 64.

${ }^{44}$ Naeem $v$ Secretary of State for Justice para 22 and 28.

45 Ibid. para 25.

${ }^{46}$ Chief Constable of West Yorkshire Police v Homer para 25.
} 
addressed them. It is submitted that this constitutes an approach which is much closer to the spirit of indirect discrimination than searching for a reason why at the prima facie stage.

\section{Conclusion}

It is unfortunate that both of these cases have drifted away from the clear principle illuminating the concept of indirect discrimination, as reiterated in Homer by Baroness Hale, namely to level the playing field by placing under scrutiny practices which, although on their face apply equally to everyone, have the effect of subjecting individuals with a particular protected characteristic

to comparative disadvantage. ${ }^{47}$ There should be no need to prove the reason why the practice has these effects or that this reason is peculiar to the protected characteristic. The key issue is whether the practice can be justified in the light of possible alternatives, and if not how it should be modified or replaced. It is here that the real focus should lie if indirect discrimination is to get anywhere close to fulfilling its mission of removing unnecessary obstacles to equal opportunity.

${ }^{47}$ Ibid. para 17. 